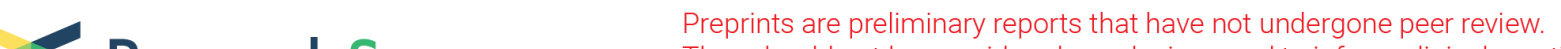 Research Square
}

\section{The Prevalence and Characteristic of Sleep Problems among Children with Fetal Alcohol Spectrum Disorders (FASD).}

Katarzyna Anna Dyląg ( $\sim$ katarzyna.dylag@dzieciecyszpital.pl )

St. Louis Children Hospital https://orcid.org/0000-0001-6886-0136

Bożena Bańdo

Saint Louis Children's Hospital

\section{Zbigniew Baran}

National Tuberculosis and Lung Diseases Institute: Instytut Gruzlicy i Chorob Pluc

\section{Paulina Dumnicka}

Jagiellonian University in Krakow Medical College Faculty of Medicine: Uniwersytet Jagiellonski

Collegium Medicum Wydzial Lekarski

Katarzyna Kowalska

Saint Louis Children's Hospital

\section{Paulina Kułaga}

St. Louis Children Hospital

Katarzyna Przybyszewska

Saint Louis Children's Hospital

Jakub Radliński

National Tuberculosis and Lung Diseases Institute: Instytut Gruzlicy i Chorob Pluc

\section{Sylvia Roozen}

Maastricht University: Universiteit Maastricht

\section{Leopold Curfs}

Maastricht University: Universiteit Maastricht

\section{Research}

Keywords: FASD, PAE, fetal alcohol syndrome, partial fetal alcohol syndrome, alcohol related neurodevelopmental disorders, sleep disorders, prenatal alcohol exposure

Posted Date: November 19th, 2020

DOl: https://doi.org/10.21203/rs.3.rs-110591/v1 
License: (c) (i) This work is licensed under a Creative Commons Attribution 4.0 International License. Read Full License 


\section{Abstract}

\section{Background}

Fetal alcohol spectrum disorders (FASD) is a group of conditions resulting from prenatal alcohol exposure (PAE). Patients with FASD experience a variety of neuropsychological symptoms resulting from central nervous system impairment. Little is known about sleep disorders associated with PAE. The objective of this study was to investigate the prevalence and characterize sleep problems among individuals with FASD.

Methods

40 patients from FASD diagnostic center (median age 8 years $(6 ; 11)$ ) diagnosed with one of the FASD diagnosis and 40 patients from the control group (median age 10 years $(8 ; 13)$ ) participated in the study. In the $1^{\text {st }}$ phase, the screening of sleep problems was performed with Child Sleep Habit Questionnaire (CSHQ) filled in by a caregiver. Those who scored above 41 points were qualified to the $2^{\text {nd }}$ phase of the study in which in-lab attended polysomnography (PSG) was performed. The measurements consisted of electroencephalographic channels, left and right electrooculograms, chin electromyogram, left and right tibialis electromyogram, electrocardiogram, ventilatory monitoring, breathing effort, pulse oximetry, snoring and body position.

Results

The number of participants with sleep disturbances was markedly higher in the study group as compared to controls ( $55 \%$ vs. $20 \%$ ). The age-adjusted odds ratio for a positive result in CSHQ was 4.31 (95\% Cl: 1.54-12.11; $p=0.005)$ for FASD patients as compared to the control group. Significant differences between the study and control groups were observed in the following subscales: sleep onset delay, night wakings , parasomnias, sleep disordered breathing, and daytime sleepiness. In PSG children from the FASD group and children from the control group experienced more arousals during the sleep than the children from the laboratory control group. ). There were no significant differences in comparison of respiratory indexes between FASD and control groups although indices in both groups were higher than previously published data for a normal population.

Conclusion

Sleep disorders are more common among individuals with FASD than among healthy children. As distorted sleep can affect daily performance and worsen neurodevelopmental issues, it is vital for the pediatricians and other FASD specialists to include the question about sleep in the anamnesis.

\section{Background}

Fetal alcohol spectrum disorders (FASD) is an umbrella term covering different diagnoses resulting from prenatal alcohol exposure (PAE). With the estimated worldwide prevalence of 22.77 (0 to 176.77)(1) FASD 
is one of the most common neurodevelopmental conditions. The principal clinical characteristic of FASD is a brain impairment associated with alcohol neurotoxicity.(2) The variety of brain functions or domains can be affected including executive functions, cognition, social skills, abstract reasoning, attention deficit/hyperactivity; adaptive behavior, social skills, psychomotor coordination(3) etc. yet each individual with FASD presents a different clinical picture. Many patients complain not only of neurobehavioral issues but also of disorders of urination(4), defecation(5), nutrition(6) and sleep, also known as "neglected problems". It is now well established from a variety of studies, that sleep disorders are much more common among children with neurodevelopmental conditions.(7) Sleep disorders affect daily performance of children and can affect the diagnostic process creating a complex clinical picture.(8) Clinical experience, anecdotal reports and qualitative studies $(9,10)$ suggest that sleep disorders are a major complaint among individuals with FASD. Although several quantitative studies have been carried out on this matter, there is still very little scientific understanding of the nature of sleep disorders in FASD. An objective of this study was to determine the prevalence of sleep disorders and characterize what sleep behaviors and sleep aspects are altered the most among persons with FASD.

\section{Material And Methods}

The study was conducted as a prospective study in the years 2018-2020.

\section{Subjects}

The study group consisted of 40 patients of FASD Diagnostic Center in St. Louis Children Hospital. The inclusion criteria were: FASD diagnosis established by a multidisciplinary team according to Hoyme 2016 criteria(11), age 3-18 at the moment of the enrollment. The exclusion criteria were: comorbid pulmonary disease causing a distorted sleep (severe asthma, cystic fibrosis), another birth defect, a known seizure disorder. The control group was selected from patients of the Gastroenterology Department of St. Louis Children Hospital diagnosed with a small intestine bacterial overgrowth (SIBO) and successfully treated. The participation was offered during a follow-up visit, after the patients were asymptomatic regarding abdominal pain for at least 3 months. The control group consisted of 18 males and 22 females, the median age was $10(8 ; 13)$. The exclusion criteria for the control group were: confirmed or unknown prenatal alcohol exposure, microcephaly, height/weight below 10th percentile, presence of facial dysmorphic features characteristic for FASD (smooth philtrum, narrow upper lip, short palpebral fissure), comorbid pulmonary disease causing distorted sleep (severe asthma, cystic fibrosis), comorbid neurologic or neurodevelopmental condition causing a distorted sleep (f.e. ADHD, spinal muscular atrophy). From each group, 40 consecutive patients eligible for the study were offered the participation. No patient met exclusion criteria. 22 patients from the study group and 7 from the control group were eligible for the second phase of the study, however, 3 patients from the study group and 2 from the control group discontinued the participation due to a caregiver's refusal (Fig. 1). Therefore, to compare the results of PSG, a control group from the retrospective data from the laboratory was formed $(n=105)$. The group was composed of the patients who had the PSG performed among typically developing children, mainly due to the request of their caregivers or primary care physicians. The inclusion criteria 
consist of: lack of comorbidities, genetic syndromes and negative result of polysomnography in the term of sleep disordered breathing (a number of breathing events per hour of sleep less than one). The group was treated as a population sample representative for the laboratory and reference intervals for sleep related parameters were calculated after removal of $10 \%$ extreme values.

\section{Methods}

The study consisted of two phases. A written consent was obtained by the researchers from the parents and children above 12 years of age. Children younger than 12 were informed about the study and all their questions were answered by a researcher. Parents/caregivers of the patients eligible for participation in the study were asked by an independent researcher to fill in the Child's Sleep Habits Questionnaire (CSHQ) - an abbreviated form (Polish version).(12) The questionnaire is an established tool for screening pediatric sleep problems. It consists of 33 questions covering the following aspects of sleep: bedtime resistance, sleep onset delay, sleep duration, sleep anxiety, night wakings, parasomnias, sleep distorted breathing and daytime sleepiness. Based on the answers of the caregivers a total sleep disturbance score was calculated. In consistency with the previous publications(12) the cutoff was established at 41 points, and patients whose score was above the cutoff were asked to participate in the second phase of the study.

In the second phase of the study in-lab attended polysomnography (PSG) was performed (Alice 6 Philips Respironics) according to AASM recommendations(13) The measurements consisted of electroencephalographic channels (01/A2, 02/A1, C3/A2, C4/A1, F3/A2, F4/A1), left and right electrooculograms, chin electromyogram, left and right tibialis electromyogram, electrocardiogram, ventilatory monitoring using thermal and pressure sensors, breathing effort monitoring using thoracic and abdominal belts, pulse oximetry, snoring and body position monitoring. Hooking-up of the subjects was performed directly before the start of the measurement, usually between 7-9 p.m. The subjects were woken up around 6 a.m. All recordings were manually scored, sleep staging and scoring breathing events were performed using pediatric criteria.(13) Sleep-stage percentages were calculated on the basis of the total sleep time (TST) and for wake periods as percentage of time in bed (TIB) - time measured from lights out to lights on. Sleep efficiency was calculated as the sleep stages percentage of TIB. Sleep latency was defined as a time from lights-off to the beginning of the first epoch considered as sleep (N1, N2, N3 REM). Stage shift means a change from one sleep stage to another. Arousals and breathing events were presented as common indices - the number of events per hour of sleep. Respiratory disturbance index (RDI) calculated as the number of respiratory events (apneas all types, hypopneas, RERA's) per hour of sleep. In the case of our study RDI effectively equals to apnea hypopnea index due to the lack of RERA's observations in all three examined groups.

\section{Statistical analysis}

The number of patients and percentage of the respective group were reported for the categories. Contingency tables were analyzed with Pearson chi-squared test. Age-adjusted logistic regression was used to confirm the difference in CSHQ results between FASD patients and controls. Continuous variables 
were exposed as median and lower and upper quartiles because not all the data were normally distributed. For comparison with previous sleep studies, selected parameters were exposed as a mean and standard deviation. Wilcoxon (Mann-Whitney) rank sum test was used to examine differences between two groups, for a greater number of groups, Kruskal-Wallis test was applied. The relation between continuous variables were examined using a linear regression model. Calculations were performed using (14)(Microsoft R Open 3.5.3) environment for statistical computing and Statistica 12.0 (StatSoft, Tulsa, OK, USA).

\section{Results}

\section{Sample characteristics}

The median age of the FASD group was 8 years $(6 ; 11)$, the group consisted of 19 males and 21 females (Table 1). Twelve percent of the patients were with at least one of the biological parents, $35 \%$ were in a foster care, whilst $52 \%$ were in adoptive families. Within FASD, the most common diagnosis was ARND (42\%), followed by pFAS (32\%) and FAS (25\%). When compared with the control group, patients from the FASD group had an equal sex distribution and body mass index (BMI) but were slightly younger (Table 1).

Table 1

Characteristics of studied patients with FASD and control subjects

\begin{tabular}{|c|c|c|c|}
\hline & FASD patients $(n=40)$ & Control group $(n=40)$ & p \\
\hline \multicolumn{4}{|l|}{ Diagnosis: } \\
\hline FAS, n (\%) & $10(25)$ & \multirow[t]{3}{*}{ NA } & \multirow[t]{3}{*}{ NA } \\
\hline pFAS, n (\%) & $13(32)$ & & \\
\hline ARND, n (\%) & $17(42)$ & & \\
\hline Age, years* & $8(6 ; 11)$ & $10(8 ; 13)$ & 0.02 \\
\hline Male sex, n (\%) & $19(47)$ & $18(45)$ & 0.8 \\
\hline \multicolumn{4}{|l|}{ Family: } \\
\hline Biological, n (\%) & $40(100)$ & $5(12)$ & \multirow[t]{3}{*}{$<0.0001$} \\
\hline Foster, n (\%) & 0 & $14(35)$ & \\
\hline Adoptive, n (\%) & 0 & $21(52)$ & \\
\hline Weight, kg & $24(17 ; 33)$ & $30(21 ; 42)$ & 0.04 \\
\hline Height, m & $129(112 ; 139)$ & $138(123 ; 153)$ & 0.02 \\
\hline $\mathrm{BMI}, \mathrm{kg} / \mathrm{m}^{2}$ & $15.2(13.9 ; 17.6)$ & $15.9(14.8 ; 18.0)$ & 0.2 \\
\hline
\end{tabular}


The number of participants with sleep disturbances, i.e. total sleep disturbance score above the cutoff, was markedly higher in the study group as compared to controls ( $55 \%$ vs. $20 \%$, Table 2 ). The ageadjusted odds ratio for a positive result in CSHQ (i.e. total sleep disturbance score > 41) was 4.31 (95\% confidence interval: $1.54-12.11 ; p=0.005)$ for FASD patients as compared to the control group. BMI was not associated with the total sleep disturbance score $>41$ among children with FASD $(p=0.09$ after age adjustment).There were no significant differences in CSHQ results (subscales and total sleep disorder score) between children diagnosed with FAS, pFAS and ARND, although those with pFAS tended to show the highest scores (Fig. 2A). Moreover, the diagnosis was not significantly associated with the percentage of positive CSHQ results [4 (40\%) of patients with FAS, $9(69 \%)$ of patients with pFAS, and $9(53 \%)$ of patients with ARND; $p=0.4$ ]. There were no significant differences in CSHQ results between FASD children depending on the type of a family, however, those in biological families tended to show the lowest scores (Fig. 2B). The type of a family was not significantly associated with the positive result in CSHQ among patients with FASD [2 (40\%) of children in biological families, $9(64 \%)$ in foster families, and $11(52 \%)$ in adoptive families; $p=0.6]$. Significant differences between the study and control groups were observed in the following subscales: sleep onset delay, night wakings, parasomnias, sleep disordered breathing, and daytime sleepiness (Table 2).

Table 2

The results of CSHQ in FASD patients and controls

\begin{tabular}{|llll|}
\hline Children's Sleep Habits Questionnaire: & FASD patients $(\mathbf{n}=\mathbf{4 0})$ & Control group $(\mathbf{n}=\mathbf{4 0})$ & $\mathbf{p}$ \\
\hline Bedtime resistance, points & $8(6 ; 10)$ & $7(7 ; 8.5)$ & 0.2 \\
\hline Sleep onset delay, points & $1(1 ; 2.5)$ & $1(1 ; 1)$ & 0.02 \\
\hline Sleep duration, points & $3(3 ; 4)$ & $3(3 ; 4)$ & 0.3 \\
\hline Sleep anxiety, points & $5(4 ; 6.5)$ & $4(4 ; 5.5)$ & 0.3 \\
\hline Night wakings, points & $4(3 ; 5)$ & $3(3 ; 4)$ & 0.01 \\
\hline Parasomnias, points & $9(8 ; 11.5)$ & $7(7 ; 8)$ & 0.0003 \\
\hline Sleep disordered breathing, points & $3(3 ; 5)$ & $3(3 ; 3)$ & 0.02 \\
\hline Daytime sleepiness, points & $11(7.5 ; 13.5)$ & $8(7 ; 9)$ & 0.0009 \\
\hline Total sleep disturbance score, points & $45(40 ; 58)$ & $39(36.5 ; 41)$ & 0.0007 \\
\hline Total sleep disturbance score $>41$ & $22(55)$ & $8(20)$ & 0.001 \\
\hline points, $n$ (\%) & & & 0.0006 \\
\hline Polysomnography, $n(\%)$ & $19(47)$ & $5(12)$ & \\
\hline
\end{tabular}

\section{Polysomnography}


Children from the study group had a distorted sleep architecture in comparison with the patients from the laboratory control group representing a population sample (Table 3). The number of stage shifts was greater, the proportion of time spent in the N1 stage of sleep and proportion of summary time of N3 and REM was significantly higher among the patients with FASD than among the patients from the laboratory control group (Table 3)). Children from the FASD group and children from the control group experienced more arousals during the sleep than the children from the laboratory control group (Table 3). There were no significant differences in comparison of respiratory indexes between FASD and control groups although indices in both groups were higher than previously published data for a normal population (Table 4). There was no relation between the arousals index and RDI in the FASD group $\left(R^{2}<0.01, p=\right.$ 0.73). The similar lack of relationship was observed between the obstructive apnea index and central apnea index $\left(R^{2}<0.18, p=0.07\right)$ and between the hypopnea index and central apnea index $\left(R^{2}=0.14, p=\right.$ $0.62)$ in FASD group. 
Table 3

Polysomnography results

\begin{tabular}{|c|c|c|c|c|}
\hline & $\begin{array}{l}\text { FASD patients } \\
(n=19)\end{array}$ & $\begin{array}{l}\text { Control } \\
\text { group }(n=5)\end{array}$ & $\begin{array}{l}\text { Laboratory control } \\
\text { group }(n=105)\end{array}$ & p \\
\hline Age, years & $7.1(5.5 ; 9.3)$ & $7.5(6.7 ; 8.7)$ & $6.5(4.9 ; 8.9)$ & 0.7 \\
\hline Male sex, n (\%) & $8(42)$ & $3(60)$ & $66(63)$ & 0.2 \\
\hline Aquisition time, min & $594(578 ; 607)$ & $\begin{array}{l}582(570 \\
584)\end{array}$ & $591(572 ; 603)$ & 0.4 \\
\hline $\mathrm{TIB}, \min$ & $548(530 ; 569)$ & $\begin{array}{l}538(529 \\
544)\end{array}$ & $543(524 ; 563)$ & 0.8 \\
\hline TST, min & $464(434 ; 507)$ & $\begin{array}{l}449(446 ; \\
480)\end{array}$ & $466(433 ; 494)$ & 0.9 \\
\hline SPT, min & $526(502 ; 543)$ & $\begin{array}{l}512(509 ; \\
534)\end{array}$ & $517(494 ; 537)$ & 0.8 \\
\hline Sleep efficiency, \%TIB & $\begin{array}{l}86.4(78.4 ; \\
91.1)\end{array}$ & $\begin{array}{l}82.6(81.4 ; \\
82.9)\end{array}$ & $86.1(79.7 ; 92.8)$ & 0.8 \\
\hline Sleep latency, min & $\begin{array}{l}22.5(7.4 \\
28,6)\end{array}$ & $\begin{array}{l}18.9(11.0 ; \\
30.2)\end{array}$ & $16.0(5.5 ; 26.1)$ & 0.5 \\
\hline Stage shifts, $n$ & $86(64 ; 97)$ & $75(57 ; 98)$ & $67(54 ; 83)$ & $0.03^{a}$ \\
\hline W, \%SPT & $9.7(3.4 ; 14.7)$ & $\begin{array}{l}\text { 12.3 (11.9; } \\
16.5)\end{array}$ & $9.8(4.2 ; 15.2)$ & 0.6 \\
\hline N1, \%TST & $4.3(2.6 ; 5.7)$ & $3.2(3.0 ; 3.7)$ & $2.4(1.8 ; 3.6)$ & $\begin{array}{l}0.005 \\
a\end{array}$ \\
\hline N2, \%TST & $\begin{array}{l}53.7(47.6 \\
58.0)\end{array}$ & $\begin{array}{l}54.4(47.4 ; \\
57.3)\end{array}$ & $50.4(46.2 ; 53.5)$ & 0.1 \\
\hline N3, \%TST & $\begin{array}{l}27.5(22.1 \\
31.5)\end{array}$ & $\begin{array}{l}26.8(24.6 \\
29.8)\end{array}$ & $29.0(25.0 ; 32.5)$ & 0.2 \\
\hline REM, \%TST & $\begin{array}{l}15.1(14.5 ; \\
19.4)\end{array}$ & $\begin{array}{l}\text { 17.8 (17.4; } \\
19.9)\end{array}$ & $17.6(14.9 ; 20.6)$ & 0.4 \\
\hline N3 + REM, \%TST & $\begin{array}{l}42.5(39.5 \\
46.5)\end{array}$ & $\begin{array}{l}42.5(37.0 \\
50.5)\end{array}$ & $46.7(42.1 ; 50.5)$ & $0.03^{a}$ \\
\hline
\end{tabular}

a significant difference between FASD patients and the laboratory control group

b significant difference between FASD patients and the control group

${ }^{\mathrm{c}}$ significant difference between control group and the laboratory control group 


\begin{tabular}{|c|c|c|c|c|}
\hline & $\begin{array}{l}\text { FASD patients } \\
(n=19)\end{array}$ & $\begin{array}{l}\text { Control } \\
\text { group }(n=5)\end{array}$ & $\begin{array}{l}\text { Laboratory control } \\
\text { group }(n=105)\end{array}$ & p \\
\hline Arousal index, events/h & $6.9(5.9 ; 8.5)$ & $8.5(7.7 ; 9.6)$ & $5.1(4.1 ; 6.2)$ & $\begin{array}{l}< \\
0.0001 \\
a, c\end{array}$ \\
\hline Total apnea index, events/h & $1.0(0.7 ; 1.8)$ & $2.1(0.8 ; 5.4)$ & & 0.3 \\
\hline Central apnea index, events/h & $1.0(0.5 ; 1.8)$ & $2.0(0.8 ; 4.3)$ & & 0.3 \\
\hline $\begin{array}{l}\text { Obstructive apnea index, } \\
\text { events/h }\end{array}$ & $0(0 ; 0.2)$ & $0(0 ; 0.6)$ & & 0.6 \\
\hline Mixed apnea index, events/h & $0(0 ; 0.1)$ & $0.1(0 ; 0.1)$ & & 0.6 \\
\hline Hypopnea index, events/h & $0.5(0 ; 1.2)$ & $0.8(0.2 ; 1.6)$ & & 0.5 \\
\hline $\begin{array}{l}\text { Obstructive apnea hipopnea } \\
\text { Index, events/h }\end{array}$ & $0.7(0.2 ; 1.3)$ & $\begin{array}{l}0.98(0.25 \\
2.75)\end{array}$ & & 0.6 \\
\hline $\begin{array}{l}\text { Respiratory disturbance } \\
\text { index, events/h }\end{array}$ & $1.7(1.0 ; 3.2)$ & $2.9(0.8 ; 7.0)$ & & 0.6 \\
\hline Minimal $\mathrm{SaO}_{2}, \%$ & $91(90 ; 92)$ & $92(86 ; 92)$ & & 0.5 \\
\hline Average $\mathrm{SaO}_{2}, \%$ & $97(96 ; 97)$ & $97(96 ; 97)$ & & 1 \\
\hline $\begin{array}{l}\text { Oxygen desaturation index, } \\
\text { events/h }\end{array}$ & $1.8(0.9 ; 2.9)$ & $2.2(0.8 ; 8.1)$ & & 0.5 \\
\hline \multicolumn{5}{|c|}{ a significant difference between FASD patients and the laboratory control group } \\
\hline \multicolumn{5}{|c|}{${ }^{b}$ significant difference between FASD patients and the control group } \\
\hline
\end{tabular}


Table 4

Polysomnography results in FASD patients and the control group exceeding the reference intervals based on "laboratory controls"

\begin{tabular}{|c|c|c|c|c|c|}
\hline & \multirow[t]{3}{*}{$\begin{array}{l}\text { Reference } \\
\text { interval }\end{array}$} & \multicolumn{4}{|c|}{$\begin{array}{l}\text { Number }(\%) \text { of patients with result above or below } \\
\text { reference interval }\end{array}$} \\
\hline & & \multicolumn{2}{|c|}{ FASD patients $(n=19)$} & \multicolumn{2}{|c|}{ Control group $(n=5)$} \\
\hline & & Below & Above & Below & Above \\
\hline Sleep efficiency, \% & $\geq 63.38$ & 0 & NA & 0 & NA \\
\hline Sleep latency, min & $0.6-85.2$ & 0 & $1(5)$ & 0 & 0 \\
\hline Stage shifts, n & $45.2-108.4$ & 0 & $1(5)$ & 0 & 0 \\
\hline W, \%SPT & $1.42-28.34$ & $1(5)$ & 0 & 0 & 0 \\
\hline N1, \%TST & $0.5-7.9$ & 0 & $2(11)$ & 0 & $1(20)$ \\
\hline N2, \%TST & $39-62.4$ & $1(5)$ & 0 & 0 & 0 \\
\hline N3, \%TST & $19.8-43.7$ & $3(16)$ & 0 & $1(20)$ & 0 \\
\hline REM, \%TST & $6.1-27.4$ & 0 & 0 & 0 & 0 \\
\hline $\begin{array}{l}\text { Arousal index, } \\
\text { events/h }\end{array}$ & $\leq 7.7$ & NA & 7 (37) & NA & $3(60)$ \\
\hline
\end{tabular}


Table 5

Comparison selected PSG indices with previous sleep studies in general children population (mean \pm standard deviation)

\begin{tabular}{|c|c|c|c|c|}
\hline & $\begin{array}{l}\text { Current } \\
\text { study }\end{array}$ & $\begin{array}{l}\text { Montgomery- } \\
\text { Downs (23) }\end{array}$ & $\begin{array}{l}\text { Montgomery- } \\
\text { Downs(23) }\end{array}$ & Goodwin(24) \\
\hline Age, range, years & $2.9-12.6$ & $3.2-5.9$ & $6.0-8.6$ & $6-11$ \\
\hline N & 19 & 153 & 388 & 480 \\
\hline TST, min & $\begin{array}{l}464 \pm \\
50.4\end{array}$ & $475.2 \pm 42.0$ & $471.6 \pm 43.7$ & $487 \pm 79.7$ \\
\hline Sleep efficiency, \%TIB & $84.8 \pm 7.9$ & $90.0 \pm 7.0$ & $89.3 \pm 7.5$ & $89.8 \pm 5.8$ \\
\hline Sleep latency, min & $\begin{array}{l}24.7 \pm \\
25.7\end{array}$ & $24.1 \pm 25.6$ & $23.0 \pm 25.3$ & $18.5 \pm 21.0$ \\
\hline W, \%TIB & $15.2 \pm 7.9$ & $9.4 \pm 7.3$ & $8.1 \pm 7.1$ & \\
\hline N1, \%TST & $4.5 \pm 2.5$ & $6.6 \pm 4.8$ & $7.1 \pm 5.5$ & $4.6 \pm 3.3$ \\
\hline N2, \%TST & $52.5 \pm 6.3$ & $41.6 \pm 7.1$ & $46.1 \pm 8.5$ & $52.0 \pm 6.1$ \\
\hline \multirow[t]{2}{*}{ N3, \%TST } & $26.8 \pm 6.2$ & S3: $6.6 \pm 2.6$ & S3: $5.5 \pm 2.9$ & $21.9 \pm 6.9$ \\
\hline & & S4: $21.6 \pm 6.2$ & S4: $18.5 \pm 6.6$ & \\
\hline REM, \%TST & $16.2 \pm 4.0$ & $23.6 \pm 4.8$ & $22.2 \pm 5.2$ & $21.5 \pm 5.0$ \\
\hline Arousal index, events/h & $7.4 \pm 2.2$ & $9.0 \pm 3.4$ & $9.5 \pm 5.3$ & \\
\hline $\begin{array}{l}\text { Total apnea index, } \\
\text { events/h }\end{array}$ & $1.8 \pm 1.8$ & $0.86 \pm 0.75$ & $0.50 \pm 0.52$ & \\
\hline $\begin{array}{l}\text { Central apnea index, } \\
\text { events/h }\end{array}$ & $1.6 \pm 1.5$ & $0.82 \pm 0.73$ & $0.45 \pm 0.49$ & $0.28 \pm 0.84$ \\
\hline $\begin{array}{l}\text { Obstructive apnea index, } \\
\text { events/h }\end{array}$ & $0.2 \pm 0.3$ & $0.03 \pm 0.1$ & $0.05 \pm 0.11$ & $0.02 \pm 0.27$ \\
\hline $\begin{array}{l}\text { Mixed apnea index, } \\
\text { events/h }\end{array}$ & $0.1 \pm 0.2$ & $0.01 \pm 0.05$ & $0.01 \pm 0.06$ & \\
\hline $\begin{array}{l}\text { Hypopnea index, } \\
\text { events/h }\end{array}$ & $1.3 \pm 3.0$ & $0.03 \pm 0.07$ & $0.10 \pm 0.18$ & \\
\hline $\begin{array}{l}\text { Apnea hypopnea index, } \\
\text { events/h }\end{array}$ & $3.2 \pm 4.4$ & $0.90 \pm 0.78$ & $0.68 \pm 0.75$ & $0.90 \pm 1.91$ \\
\hline Minimal $\mathrm{SaO}_{2}, \%$ & $90.1 \pm 3.1$ & $92.7 \pm 4.5$ & $92.6 \pm 3.6$ & \\
\hline Average $\mathrm{SaO}_{2}, \%$ & $96.4 \pm 1.2$ & & & \\
\hline
\end{tabular}




\section{Discussion}

According to our results every second child with FASD experiences sleep disorders. This finding is consistent with the result of the research published by Goril et al.(15) who estimated the prevalence of sleep disorders among individuals with FASD to $58 \%$. On the other hand, Chen et al.(16) established a prevalence rate at $85 \%$. Although similarly to our study, Chen et al. used the CSHQ, they classified children with the borderline Total Score of 41 as having sleep disturbances whilst we, following the CSHQ instruction(12,17), qualified only the children who scored above 41 . However, 7 children from the FASD group (17.5\%) and 7 children from the control group (17.5\%) had a Total score equal with 41 . The subscales revealed that sleep onset delay, night wakings, parasomnias, sleep disordered breathing and daytime sleepiness occur more frequently among individuals with FASD. The trend, although without statistical significance, was also observed regarding sleep anxiety and bedtime resistance. These results are in agreement with those obtained by Chen et al.(16) who reported an increased frequency of sleep problems in all 8 subdomains of CSHQ. Our observations are also in line with the findings reported by Wengel et al. who indicated that patients with FASD complained about bedtime resistance, shortened sleep duration, sleep anxiety, night awakenings and parasomnias.(18)

The data on the results of the polysomnography among FASD patients is scarce. Our findings match those published by Chen et al.(16) although we observed that not only obstructive but also central apneic events were more frequent among individuals with FASD. However, as the authors suggested, given the small sample size, their data should be considered exploratory. Similarly, Goril et al.(15) indicated an increased sleep fragmentation and an increased predisposition to apneic/hypopneic events, interestingly, the increased AHI was only observed in the young children in their sample. Alvik et al., Troese et al. and Scher et al(19-21) demonstrated that infants with prenatal alcohol exposure tend to present fragmented sleep and experience more arousals, however, these studies were performed with a different methodology. A similar finding was documented by Volgin et al. on an animal model of PAE.(22) In our study sleep in FASD subjects was less stable than in the control group which is mainly expressed in a greater number of stage shifts, an increased amount of stage $\mathrm{N} 1$ and a higher number of arousals. The lack of relation between arousals and breathing events suggests that the subset of arousals has other than a respiratory cause. Interestingly, in comparison to general population samples $(23,24)$ (Table 4) the results are not consistent. Montgomery Downs reported the amount of N1 sleep higher than in our subjects but Goodwin reported it approximately at the same level. The amount of N3 is comparable to the Montgomery-Downs sample but much higher than in the Goodwin sample. The percentage of REM sleep is the lowest in our FASD group in comparison to both studies. The amount of this stage is also lowered in our control groups, so the proportion of laboratory related and FASD related factors is difficult to be examined. However, insufficiency of REM sleep is one of the major causes of neurocognitive problems. The number of arousals is lower in comparison to both studies.

Both examined groups (FASD and control) had much more detected breathing events than reported in general population samples. It is clearly visible in all compared indices (Table 4), however for some of them (hypopnea index) it could be a combined result of our groups characteristics and differences in the 
scoring criteria. The changes in the hypopnea definition which were introduced in version 2 of AASM manual lead to an increased number of detected events. According to the authors' knowledge there is no information about how those changes affect hypopnea index results in children population but the hypopnea index in our study is larger by an order of magnitude which is more than a potential impact of definition changes. The central apnea index in the FASD group is greater by factor of two, even though current children central apnea definition is more restrictive. The cause of sleep problems among individuals with FASD remains uncertain. Chen et al. suggested, using the rat model, that PAE affects expression of the genes responsible for the circadian function of $\beta$-endorphin neurons in the hypothalamus.(25) On the other hand, Goril et al. determined that children with FASD have an altered melatonin profile, which can affect the sleep cycle.(15) The central apneic/hypopneic events result from the central nervous damage secondary to prenatal alcohol exposure, as it has been established that alcohol affects the neurons in the variety of modes. (26) It is worth mentioning that obstructive apneic/hypopneic events were frequent among children with FASD, however, none of the patients was obese. Nevertheless, the anatomical features connected to FASD - micrognathia, high-arched palate may result in the airway obstruction. $(27,28)$

This is the first study to comprehensively assess the sleep problems among children with FASD in a relatively big sample with a control group. Due to organizational reasons the enrollment to the both groups was performed simultaneously which resulted in the negligible age difference between the groups. However, patients from both groups were within the age frame for CSHQ (3-18 years) and all differences observed between the groups were independent of age. CSHQ is a subjective sleep problems assessment which might be considered a limitation of this study. Only the patients screened by CSHQ were offered the objective sleep evaluation. The majority of parents in the study group were either foster or adoptive parents yet, the patients from the control group were in biological families. It is well established that foster and adoptive parents of FASD children experience a lot of distress and they present a tendency to an overprotective attitude(29) which can be a potential source of bias in the selfreport. Moreover, the 3 patients from the study group and 3 from the control group withdrew their consent and discontinued the study after the invitation to the second phase of the study. However, even with this limitation many patients completed the PSG and the results can be considered representative.

Notwithstanding the limitations, the study offers the overview of the frequency and nature of sleep problems among individuals with FASD. Further experimental investigations are needed to determine the mechanisms that contribute to this phenomenon as well as the treatment options. From the clinical perspective it is important for the physicians and psychologist taking care for patients with FASD to include the question about the sleep quality in the history taking and try to address this issue.

\section{Conclusion}

In conclusion, individuals with FASD have an increased risk of sleep disorders among which distorted sleep architecture and apneic/hypopneic events are the most common. 


\section{List Of Abbreviations}

AASM - American Academy of Sleep Medicine

ADHD- Attention Deficit Hyperactivity Disorder

AHI- Apnea-Hypopnea Index

ARND- Alcohol- Related Neurodevelopmental Disorder

CSHQ- Child's Sleep Habits Questionnaire

FASD- Fetal Alcohol Spectrum Disorders

FAS- Fetal Alcohol Syndrome

PAE- Prenatal Alcohol Exposure

PFAS- Partial Fetal Alcohol Syndrome

PSG- Polysomngraphy

RDI- . Respiratory Disturbance Index

REM- Rapid Eye Movement

RERA- Respiratory Effort Related Arousal

TIB-Time In ed

TST- Total Sleep Time

\section{Declarations}

Ethics

The study was approved by the regional ethical committee by Regional Board of Physicians (approval number: 123/kbl/oil/2018). The study complies with the Declaration of Helsinki.

\section{Consent for publication}

Not applicable

\section{Data availability}


The datasets used and/or analyzed during the current study are available from the corresponding author on reasonable request.

\section{Competing interests}

The authors declare that they have no competing interests

\section{Funding}

The article was prepared within the frame of the research project financed by the National Health Program for 2016-2020 (grant number: 60/43/3.4.2/18/DEA coordinated by State Agency for the Prevention of Alcohol Related Problems). The funding covered the costs of polysomnography, main researcher salary, language editing and statistical analyses.

\section{Authors' contributions}

KD designed the study, supervised the study, analyzed the data and drafted the manuscript

$\mathrm{ZB}, \mathrm{PK}, \mathrm{KP}, \mathrm{KK}, \mathrm{BB}, \mathrm{JR}$ collected the data

JR, PD performed the statistical analyses

SR, LC, PD, JR drafted the manuscript

All authors approved the submitted version of the manuscript.

\section{Acknowledgments}

The researchers would like to thank Dr. Judith Owens for the permission to use the Child's Sleep Habits Questionnaire (CSHQ)

\section{References}

1. Roozen S, Peters G-JY, Kok G, Townend D, Nijhuis J, Curfs L. Worldwide Prevalence of Fetal Alcohol Spectrum Disorders: A Systematic Literature Review Including Meta-Analysis. Alcohol Clin Exp Res [Internet]. 2016;40(1):18-32. Available from: http://doi.wiley.com/10.1111/acer.12939

2. Ehrhart F, Roozen S, Verbeek J, Koek G, Kok G, van Kranen H, et al. Review and gap analysis: molecular pathways leading to fetal alcohol spectrum disorders [Internet]. Vol. 24, Molecular Psychiatry. Nature Publishing Group; 2019 [cited 2020 Nov 4]. p. 10-7. Available from: https://doi.org/10.1038/s41380-018-0095-4 
3. Kodituwakku P, Kodituwakku E. Cognitive and Behavioral Profiles of Children with Fetal Alcohol Spectrum Disorders. Curr Dev Disord Reports. 2014 Sep 17;1(3):149-60.

4. Roozen S, Olivier L, Niemczyk J, von Gontard A, Peters G-JY, Kok G, et al. Nocturnal incontinence in children with fetal alcohol spectrum disorders (FASD) in a South African cohort. J Pediatr Urol [Internet]. 2017 Mar 23 [cited 2017 Apr 15]; Available from:

http://www.ncbi.nlm.nih.gov/pubmed/28381366

5. Olivier L, Urban M, Chersich M, Temmerman M, Viljoen D. Burden of fetal alcohol syndrome in a rural West Coast area of South Africa. South African Med J [Internet]. 2013 Mar 18 [cited 2018 Sep 30];103(6):402. Available from: http://www.samj.org.za/index.php/samj/article/view/6249

6. Amos-Kroohs RM, Fink BA, Smith CJ, Chin L, Van Calcar SC, Wozniak JR, et al. Abnormal Eating Behaviors Are Common in Children with Fetal Alcohol Spectrum Disorder. J Pediatr [Internet]. 2016 Feb [cited 2019 Aug 29];169:194-200.e1. Available from:

http://www.ncbi.nlm.nih.gov/pubmed/26608087

7. Heussler HS, Hiscock H. Sleep in children with neurodevelopmental difficulties. J Paediatr Child Health [Internet]. 2018 Oct 1 [cited 2020 Sep 3];54(10):1142-7. Available from: http://doi.wiley.com/10.1111/jpc.14164

8. Robinson-Shelton A, Malow BA. Sleep Disturbances in Neurodevelopmental Disorders [Internet]. Vol. 18, Current Psychiatry Reports. Current Medicine Group LLC 1; 2016 [cited 2020 Sep 3]. p. 1-8. Available from: https://pubmed.ncbi.nlm.nih.gov/26719309/

9. Ipsiroglu OS, Mckellin WH, Carey N, Loock C. Social Science \& Medicine “ They silently live in terror . " why sleep problems and night-time related quality-of-life are missed in children with a fetal alcohol spectrum disorder. Soc Sci Med [Internet]. 2013;79:76-83. Available from:

http://dx.doi.org/10.1016/j.socscimed.2012.10.027

10. Steinhausen HC, Spohr HL. Long-term outcome of children with fetal alcohol syndrome: Psychopathology, behavior, and intelligence. In: Alcoholism: Clinical and Experimental Research [Internet]. John Wiley \& Sons, Ltd; 1998 [cited 2020 Sep 26]. p. 334-8. Available from: https://onlinelibrary.wiley.com/doi/full/10.1111/j.1530-0277.1998.tb03657.x

11. Hoyme HE, Kalberg WO, Elliott AJ, Blankenship J, Buckley D, Marais A-S, et al. Updated Clinical Guidelines for Diagnosing Fetal Alcohol Spectrum Disorders. Pediatrics. 2016 Aug;138(2).

12. Owens JA, Spirito A, McGuinn M. The Children's Sleep Habits Questionnaire (CSHQ): psychometric properties of a survey instrument for school-aged children. Sleep. 2000 Dec;23(8):1043-51.

13. Berry RB, Brooks R, Gamaldo CE, Harding SM, Marcus CLCL, Vaughn B V, et al. The AASM manual for the scoring of sleep and associated events: rules, terminology and technical specifications, version 2.5. Darien, IL: American Academy of Sleep Medicine; 2018.

14. R Core Team. R: A Language and Environment for Statistical Computing [Internet]. Vienna, Austria: R Foundation for Statistical Computing; 2019. Available from: https://www.r-project.org/

15. Goril S, Zalai D, Scott L, Shapiro CM. Sleep and melatonin secretion abnormalities in children and adolescents with fetal alcohol spectrum disorders. Sleep Med [Internet]. 2016;23:59-64. Available 
from: http://dx.doi.org/10.1016/j.sleep.2016.06.002

16. Chen ML, Olson HC, Ph D, Picciano JF, Starr JR, Ph D, et al. Sleep Problems in Children with Fetal Alcohol Spectrum Disorders. 2012;8(4).

17. Owens JA, Spirito A, McGuinn M, Nobile C. Sleep habits and sleep disturbance in elementary schoolaged children. J Dev Behav Pediatr [Internet]. 2000 [cited 2020 Sep 24];21(1):27-36. Available from: https://pubmed.ncbi.nlm.nih.gov/10706346/

18. Wengel T, Hanlon-Dearman AC, Fjeldsted B. Sleep and sensory characteristics in young children with fetal alcohol spectrum disorder. J Dev Behav Pediatr. 2011 Jun;32(5):384-92.

19. Alvik A, Mari A, Aalen OO, Lindemann R. Early Human Development Binge alcohol exposure once a week in early pregnancy predicts temperament and sleeping problems in the infant. Early Hum Dev [Internet]. 2011;87(12):827-33. Available from: http://dx.doi.org/10.1016/j.earlhumdev.2011.06.009

20. Troese M, Fukumizu M, Sallinen BJ, Gilles AA, Wellman JD, Paul JA, et al. Sleep fragmentation and evidence for sleep debt in alcohol-exposed infants. 2008;577-85.

21. Scher MS, Richardson GA, Coble PA, Day NL, Stoffer DS. The Effects of Prenatal Alcohol and Marijuana Exposure: Disturbances in Neonatal Sleep Cycling and Arousal1. 1988;24(1).

22. Volgin D V., Kubin L. Reduced sleep and impaired sleep initiation in adult male rats exposed to alcohol during early postnatal period. Behav Brain Res [Internet]. 2012 Sep 1 [cited 2020 Sep 28];234(1):38-42. Available from: /pmc/articles/PMC3412616/?report=abstract

23. Montgomery-Downs HE, O'Brien LM, Gulliver TE, Gozal D. Polysomnographic characteristics in normal preschool and early school-aged children. Pediatrics [Internet]. 2006 Mar;117(3):741-53. Available from: http://www.ncbi.nlm.nih.gov/pubmed/16510654

24. Goodwin JL, Kaemingk KL, Mulvaney SA, Morgan WJ, Quan SF. Clinical screening of school children for polysomnography to detect sleep-disordered breathing-the Tucson Children's Assessment of Sleep Apnea study (TuCASA). J Clin Sleep Med [Internet]. 2005;1(3):247-54. Available from: http://www.ncbi.nlm.nih.gov/pmc/articles/PMC1307497/

25. Chen CP, Kuhn P, Advis JP, Sarkar DK. Prenatal ethanol exposure alters the expression of period genes governing the circadian function of $b$-endorphin neurons in the hypothalamus. 2006;1026-33.

26. Goodlett CR, Horn KH. Mechanisms of Alcohol-Induced Damage to the Developing Nervous System.

27. Astley SJ, Clarren SK. Measuring the facial phenotype of individuals with prenatal alcohol exposure: correlations with brain dysfunction. Alcohol Alcohol [Internet]. 2001 Mar 1 [cited 2019 Jul 21];36(2):147-59. Available from: http://www.ncbi.nlm.nih.gov/pubmed/11259212

28. Del Campo M, Jones KL. A review of the physical features of the fetal alcohol spectrum disorders. Eur J Med Genet. 2017 Jan;60(1):55-64.

29. Petrenko CLM, Alto ME, Hart AR, Freeze SM, Cole LL. "I'm Doing My Part, I Just Need Help From the Community": Intervention Implications of Foster and Adoptive Parents' Experiences Raising Children and Young Adults With FASD. J Fam Nurs [Internet]. 2019 May 1 [cited 2020 Sep 24];25(2):314-47. Available from: https://pubmed.ncbi.nlm.nih.gov/31079560/ 


\section{Figures}

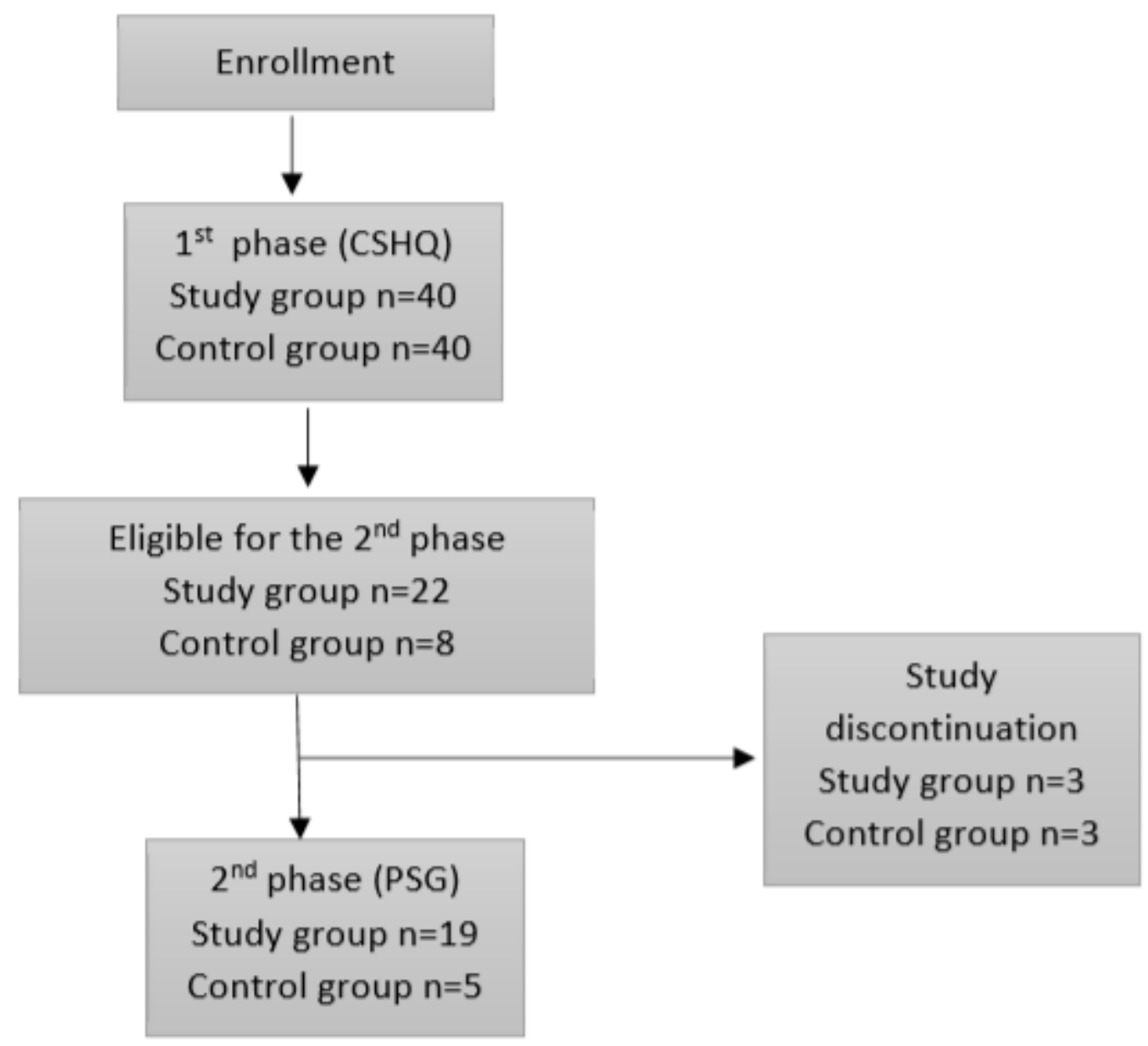

Figure 1

Study diagram 

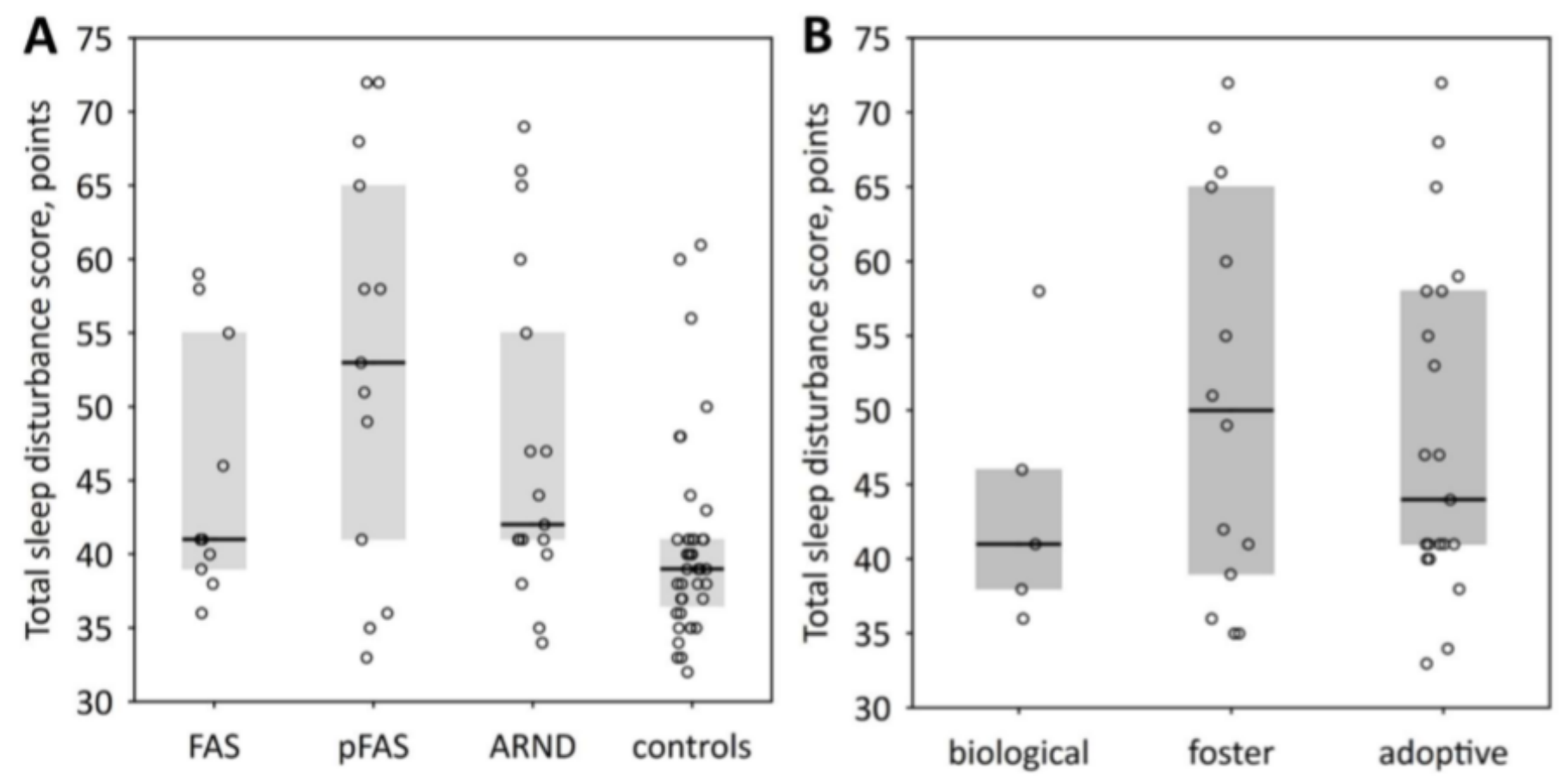

Figure 2

Total sleep disturbance score in the studied children with FASD according to diagnosis in comparison with healthy controls $(A)$ and according to the type of a family (B). There were no significant differences between FAS, pFAS and ARND patients $(p=0.4)$ and between FASD patients in biological, foster or adoptive families $(p=0.6)$. The data are shown as median (central line), interquartile range (box) and raw data (points). 